\title{
Formação de professores em serviço: fragilidades e descompassos no enfrentamento do fracasso escolar
}

Norinês Panicacci Bahia

Universidade Metodista de São Paulo

\section{Resumo}

Este artigo apresenta resultados de um estudo realizado em uma escola pública da rede estadual de São Paulo, no município de Diadema, durante três anos. Acompanhou-se a trajetória de 52 alunos que participaram do Projeto Classes de Aceleração, em 1999, e o retorno destes para o ensino regular, em 2000 e 2001, com uma proposta de Progressão Continuada. 0 artigo prioriza reflexões sobre o desempenho dos alunos que frequentaram as Classes de Aceleração e, posteriormente, seguiram estudos nas séries finais do Ensino Fundamental ( $5^{\mathrm{a}}$ a $8^{\mathrm{a}}$ séries) e também sobre o preparo (capacitação) dos professores diante da implantação dessas ações. 0 estudo de caso foi realizado por meio de observações em salas de aula e entrevistas com alunos, professores e coordenação. Os resultados apontam para alguns descompassos: entre os professores, sobre a compreensão dos objetivos e os pressupostos do projeto Classes de Aceleração; envolvimento diferenciado dos professores quanto aos problemas ou às dificuldades de aprendizagem apresentadas pelos alunos; a proposição de programas de capacitação e/ou orientações de preparo dos professores para a implantação dos dois projetos que ocorre apenas para os professores das Classes de Aceleração e não para os demais. 0 propósito das ações governamentais para o combate à defasagem idade-série, bem como para o alcance de uma escola de qualidade, não é observado no estudo. Muito pelo contrário. Ao invés de uma inclusão dos excluídos na escola, foi observada a sua reclusão, porque não se está garantindo a melhoria do desempenho dos alunos.

\section{Palavras-chave}

Formação de professores - Fracasso escolar - Classes de aceleração - Progressão continuada. 


\section{In-service teacher education: frailties and dissonances in the struggle against school failure}

Norinês Panicacci Bahia

Universidade Metodista de São Paulo

\begin{abstract}
This article brings results from a 3-year study conducted with a school located in the city of Diadema, and belonging to the State of São Paulo public school system. The study followed the trajectory of 52 students who took part in the Acceleration Classes Project (Projeto Classes de Aceleração) during 1999, and who went back into regular schooling in 2000 and 2001 under a regime of Continued Progression. The article concentrates on reflections about the performance of students that attended Acceleration Classes and later continued their studies in the final series of Fundamental Education (5th to 8th grades), and also on the degree of preparation (capacitation) of teachers with respect to the implementation of these actions. The case study was carried out through observations in the classroom and interviews with pupils, teachers, and coordinators. The results point to some dissonances: among teachers, on the understanding of objectives and assumptions of the Acceleration Classes Project; different degrees of teachers' involvement with learning difficulties or problems displayed by the students; the offer of teacher capacitation programs and/or preparation supervision geared towards the two projects is made only to teachers in Acceleration Classes, and not to the others. The purpose of governmental actions to deal with age-series gaps, as well as to move towards a quality school did not seem to be achieved here. On the contrary, instead of the inclusion of the excluded into the school, what was observed was their reclusion, since the improvement of pupils' performance has not been seen to.
\end{abstract}

\section{Keywords}

Teacher education - School failure - Acceleration Classes Continued progression.
Contact:

Norinês Panicacci Bahia

Rua Tupi, 634, ap. 51

01233-000 - São Paulo - SP

e-mail: nbahia@terra.com.br 
Este artigo - elaborado a partir da tese de doutorado' (Bahia, 2002) - apresenta os resultados da análise de duas propostas implantadas na rede pública de ensino paulista - o Projeto Classes de Aceleração (1996/1999) e o Regime de Progressão Continuada (1997) -, que tiveram como objetivo o enfrentamento do fracasso escolar. Prioriza reflexões não só sobre o desempenho dos alunos que frequentaram as Classes de Aceleração e que seguiram os estudos nas séries finais do Ensino Fundamental ( 5 a a $8^{\text {a }}$ séries) como também sobre o preparo (capacitação) dos professores diante da implantação dessas ações.

Esses dois projetos fizeram parte do Programa de Reorganização da Trajetória Escolar do Ensino Fundamental da Secretaria da Educação do Estado de São Paulo - SEESP: o projeto Classes de Aceleração (1996/1997), proposto com o objetivo de recuperar a defasagem idadesérie a que estavam submetidos os alunos multirrepetentes do Ciclo Básico à $4^{\text {a }}$ série; e o regime de Progressão Continuada (1997 até a presente data), permitindo que a organização escolar seriada fosse substituída por um ou mais ciclos de estudos, com a finalidade de superar a fragmentação do currículo e favorecer a diminuição dos índices de repetência e evasão.

Em relação ao preparo dos professores da rede ou à formação em serviço para a implantação desses projetos, pudemos observar que, para as Classes de Aceleração, foram organizadas ações pontuais de capacitação e acompanhamento em termos de sua adequação às necessidades dos professores e alunos, mas poucas ações foram realizadas em relação aos desdobramentos na escola, ou seja, não houve um preparo adequado para os professores que receberiam esses alunos nas séries subsequentes ( $5^{\mathrm{a}}$ a $8^{\text {a }}$ séries do Ensino Fundamental).

Quanto à implantação do regime de Progressão Continuada, muito pouco foi proposto em relação à formação dos professores em serviço para a compreensão dos pressupostos. As poucas ações foram restritas a algumas orientações, nas delegacias de ensino ${ }^{2}$, para dire- tores e coordenadores, que deveriam, após isso, levá-las para os professores nas escolas.

Apesar de a proposta de um programa de capacitação acompanhar a implantação das Classes de Aceleração, ela ocorreu fora da escola - nas delegacias de ensino - para os professores e coordenadores. Contudo, se não houver efetivamente ações descentralizadas de capacitação dos professores, as discussões e reflexões sobre a prática cotidiana ficam do lado de fora:

[...] a escola é uma unidade de uma outra ordem, é uma instituição. A questão da qualidade do ensino é, pois, uma questão institucional. São as escolas que precisam ser melhoradas. Sem este esforço institucional, o aperfeiçoamento isolado de docentes não garante que essa eventual melhoria do professor encontre na prática as condições propícias para uma melhoria do ensino. (Azanha, 1998, p. 58)

Acreditamos que a qualidade do ensino depende da existência de uma organização escolar eficiente, que desenvolva um projeto pedagógico articulado por meio da mobilização e do compromisso dos diretores, coordenadores, professores e comunidade, tornando a escola um local de articulação profissional. Além disso, se não houver uma articulação também das ações desenvolvidas na escola e um acompanhamento efetivo dos alunos provenientes de projetos pontuais - como, por exemplo, as Classes de Aceleração -, resultados positivos serão pouco observados, tendo em vista, pela própria desorganização interna da escola, a descontinuidade do acompanhamento e o despreparo dos profissionais que receberam esses alunos.

\footnotetext{
1. Nesta, as discussões sobre fracasso escolar e exclusão social apoiaram-se, especialmente, em Patto (2000a, 2000b), Ferraro (1999), Klein e Ribeiro (1991; 1995), Gentili (1998); sobre formação de professores especialmente em Azanha (1998), Nóvoa (1992a; 1992b) e Zeichner (1993). Foi realizada também uma análise dos principais documentos oficiais para a implantação das Classes de Aceleração e do Regime de Progressão Continuada da SEESP.

2. Atuais diretorias de ensino.
} 
Outra questão que merece ser observada é que não estamos mais discutindo exclusão escolar como um fenômeno perverso, observado por muitos anos, quando se referia à desistência dos alunos do sistema escolar após sucessivas reprovações, e que gerava os altíssimos índices de evasão. Da mesma forma, não discutimos mais exclusão escolar pela questão do não acesso à escola, porque não há mais falta de vagas. A discussão, agora, acerca da exclusão, refere-se muito mais à situação de exclusão na escola (Ferraro, 1999), e que podemos entender também como uma reclusão dos excluídos, ou seja, aquela parcela de alunos que continua na escola, mas que efetivamente não pertence a ela.

Se por muitos anos assistimos à imensa evasão dos alunos de nossas escolas, hoje a parcela dos alunos marcada pelo fracasso permanece nela. A situação dos que permanecem na escola, mas não aprendem - a exclusão na escola -, parece-nos igual à situação dos alunos que a abandonavam - a exclusão da escola do ponto de vista da negação de direitos, porque permanecer e continuar excluído dos saberes e dos conhecimentos demonstra inadequação e incompetência de um sistema de ensino.

\section{O Projeto Classes de Aceleração (1996)}

Em 1996, a SEESP implantou na rede de ensino o Projeto Reorganização da Trajetória Escolar - Classes de Aceleração - com a intenção de recuperar o percurso escolar dos alunos em situação de defasagem idade-série, especialmente os multirrepetentes do Ciclo Básico ( $1^{\text {a }}$ e $2^{\text {a }}$ séries) à $4^{\text {a }}$ série do Ensino Fundamental (São Paulo, 1996).

0 agrupamento de alunos para compor as Classes de Aceleração seguia o critério de defasagem idade-série, ou seja, as Classes de Aceleração 1 - CA 1 - eram formadas por alunos que estavam com dez anos de idade, ou mais, e que ainda cursavam o Ciclo Básico (antigas $1^{\text {a }}$ e $2^{\text {a }}$ séries do Ensino Fundamental), e as Classes de Aceleração 11 - CA 11 - eram formadas por alunos das $3^{a}$ e/ou $4^{a}$ séries que estavam com onze anos de idade ou mais. Esses alunos, após um ano frequentando as Classes de Aceleração, dependendo do desempenho apresentado, eram encaminhados para as séries regulares do Ensino Fundamental, ou seja, os alunos das CA 1 poderiam ser encaminhados para a $4^{\text {a }}$ ou a $5^{\text {a }}$ séries ou CA 11 , e os alunos das CA 11 , para a $5^{\text {a }}$ série.

A ideia de aceleração da aprendizagem ou correção do fluxo idade-série nos parece completamente equivocada a partir dos próprios critérios de encaminhamentos de alunos para as Classes de Aceleração. Como podemos observar, os alunos com 12 anos de idade que estivessem numa $4^{\text {a }}$ série em 1995 seriam colocados em CA 11 em 1996 e, no final desse ano, encaminhados para a $5^{\text {a }}$ série. Logo, não só não "avançariam" como ficariam mais um ano numa classe de aceleração, em 1996, fora do sistema regular de ensino, que os devolveria, em 1997, para uma série subsequente. Normalmente, seriam encaminhados - se não fossem reprovados - à $5^{\text {a }}$ série.

A implantação desse Projeto contou com um programa de capacitação, com duração de 120 horas anuais, para os professores e coordenadores dessas classes, bem como para os responsáveis pelo seu acompanhamento nas delegacias de ensino de todo o estado de São Paulo, no caso, supervisores de ensino e assistentes técnico-pedagógicos. Essas 120 horas de capacitação (distribuídas em encontros bimestrais de dois a três dias) ocorriam nas delegacias de ensino e eram ministradas/coordenadas por um capacitador do Centro de Estudos e Pesquisas em Educação, Cultura e Ação Comunitária - $\mathrm{CENPEC}^{3}$. Nesses encontros, os capacitadores aprofundavam reflexões teóricas sobre os diversos temas e as atividades propostas nos materiais de apoio ao professor,

3. 0 CENPEC, em parceria com a SEESP, foi o responsável pela produção dos materiais de apoio pedagógico para os professores das Classes de Aceleração (Coleção Ensinar pra Valer) e do material didático para os alunos (Coleção Aprender pra Valer) e, também, pela capacitação e acompanhamento do trabalho dos professores, coordenadores, supervisores e assistentes técnico-pedagógicos envolvidos no projeto. 
bem como eram discutidas as práticas e as intervenções dos professores das Classes de Aceleração, visando o fortalecimento e a reflexão teórico-prática dos envolvidos.

Os poucos estudos realizados sobre o desempenho dos alunos egressos, quando retornam às séries regulares, referem-se ao ano subsequente àquele em que estes frequentaram as Classes de Aceleração (como em Placco; André; Almeida, 1999; Brasil/MEC, 1998). Não há estudos que tenham analisado e acompanhado o desempenho desses alunos após três ou quatro anos do Projeto.

\section{O Regime de Progressão Continuada (1997)}

A Deliberação CEE nº 09/97 instituiu no Sistema de Ensino do Estado de São Paulo o Regime de Progressão Continuada no Ensino Fundamental, que foi adotado pela SEESP (São Paulo, 1997).

A Progressão Continuada permite que a organização escolar seriada seja substituída por um ou mais ciclos de estudos, que tem por finalidade superar a fragmentação do currículo com vistas às características dos alunos, favorecendo a diminuição dos índices de repetência e evasão. A SEESP adotou o Regime de Progressão Continuada organizando o Ensino Fundamental em dois ciclos: Ciclo $1-$ da $1^{\text {a }}$ à $4^{\text {a }}$ série $-\mathrm{e}$ Ciclo $11-$ da $5^{\text {a }}$ à $8^{\text {a }}$ série. Altera-se, assim, radicalmente, a forma de avaliação dos alunos que, ao final de cada ano letivo, eram aprovados ou não para as séries subsequentes. Agora, apenas ao final da última série de cada ciclo, na $4^{\text {a }}$ ou na $8^{a}$ série, o aluno pode ser retido.

Essa medida previu a organização de mecanismos atrelados ao projeto educacional de implantação desse regime para assegurar: avaliação institucional (interna e externa); avaliação da aprendizagem ao longo do processo, conduzindo a uma avaliação contínua e cumulativa da aprendizagem do aluno, de modo a permitir a apreciação de seu desempenho em todo o ciclo; atividades de reforço e de recu- peração paralelas e contínuas ao longo do processo e, se necessário, ao final do ciclo ou nível; meios alternativos de adaptação, reforço, reclassificação, avanço, reconhecimento, aproveitamento e aceleração de estudos; indicadores de desempenho; controle da frequência dos alunos; contínua melhoria do ensino; forma de implantação, implementação e avaliação do projeto; dispositivos regimentais adequados; articulação com as famílias no acompanhamento do aluno ao longo do processo, fornecendolhes informações sistemáticas sobre frequência e aproveitamento escolar.

Entender que esse sistema não prega a promoção automática nem o rebaixamento do ensino não foi, e não tem sido, tarefa fácil. Equívocos em relação à essência dessa proposta - que é a de promover aprendizagens significativas por meio de vários instrumentos e ações organizadas - provocaram atitudes de descrença em relação à eficácia desse sistema de avaliação, até porque outros fatores contribuíram para que ele fosse desacreditado como, por exemplo, a distância entre as intenções oficiais e o que efetivamente ocorreu no cotidiano escolar.

Além disso, a implantação de um sistema de avaliação como esse, sem o devido preparo dos profissionais para a compreensão dos fundamentos e, ainda, sem os investimentos de apoio, orientação e acompanhamento do trabalho pedagógico, pode possibilitar que práticas de promoção de alunos ocorram sem o domínio necessário ou a compreensão de muitos conteúdos de ensino - e isso foi observado.

\section{O estudo de caso}

A opção por um estudo de caso ocorreu pela possibilidade de realizarmos, por meio dessa metodologia, uma observação detalhada do que pretendíamos acompanhar: a trajetória de alunos, no período de 1999 a 2001, em uma escola da rede pública de Ensino Fundamental, participante do Projeto Classes de Aceleração, e a reinserção desses alunos no ensino regular, 
organizado por ciclos, em que prevalece um modelo de avaliação de Progressão Continuada. Além disso, possibilitou também uma aproximação com os professores e a coordenação para a realização de uma investigação acerca da preparação dos profissionais da escola e dos procedimentos de apoio e de acompanhamento da implantação dos projetos com as observações em salas de aula e a realização de entrevistas com os sujeitos envolvidos.

Foi selecionada uma escola estadual da periferia do município de Diadema por ela possuir altos índices de retenção e evasão de alunos. A escola localiza-se no bairro de Vila Paulina e o nível de ensino oferecido é o Fundamental, organizado em dois ciclos: $1^{\circ}$ ciclo $1^{\text {a }}$ a $4^{\text {a }}$ séries - e $2^{\circ}$ ciclo $-5^{\text {a }}$ a $8^{\text {a }}$ séries. Em 1999, a escola atendia 1.222 alunos (572 alunos no $1^{\circ}$ ciclo e 650 alunos no $2^{\circ}$ ciclo) e contava com 32 professores: a maioria (29) em regime Admitidos em Caráter Temporário - ACT - e apenas 3 efetivos.

Essa escola participou do Projeto Classes de Aceleração de 1996 até 1999, com uma turma em 1996 e, a partir de 1997, com duas por ano (uma em cada período - manhã e tarde).

\section{Sobre os professores}

A maior dificuldade encontrada foi conseguir mobilizar e sensibilizar os professores para participarem da pesquisa, ou seja, levá-los a responder, num primeiro momento, a um questionário com dados pessoais sobre formação e atualização profissionais, atuação na escola e opiniões sobre os dois projetos. Em outro momento, foram realizadas entrevistas com os professores das Classes de Aceleração, a coordenação, os professores das $5^{\text {a }}$ a $8^{\text {a }}$ séries e alguns alunos, além de observações em salas de aula.

Em síntese, a análise de todo o material coletado possibilitou perceber que a escola apresentava algumas contradições tanto em relação às condições físicas e materiais quanto em relação às opiniões dos professores so- bre várias questões. Apesar da precariedade do prédio escolar em termos das instalações, a quantidade de material disponível para professores e alunos chegava a ser surpreendente. Notamos, também, pelo contato mantido com a coordenação e com alguns professores, que havia efetivamente uma grande preocupação em proporcionar aos professores, mediante as reuniões de Horário de Trabalho Pedagógico Coletivo - HTPC -, uma vez por semana, todo o apoio necessário em relação às dificuldades sentidas em sala de aula, porém a participação dos professores nessas reuniões era mínima.

Em relação ao corpo docente, um dado que chamava a atenção se referia ao número reduzido de professores efetivos. Discutindo um pouco mais sobre esse aspecto, a coordenação alegava ser essa uma característica da maioria das escolas localizadas em regiões de muita pobreza, afastadas e de difícil acesso, como era o caso daquela escola. Essa situação é entendida como promotora de uma alta rotatividade de professores, o que contribui não só para o pouco vínculo com os alunos, mas também para as muitas faltas dos docentes - estes são, sem dúvida, elementos desestabilizadores das relações interpessoais.

Percebemos grande divergência nas opiniões dos professores sobre o desempenho dos alunos que participaram do projeto de aceleração e que estavam em séries do $2^{\circ}$ ciclo $\left(5^{\mathrm{a}}\right.$ a $8^{a}$ séries). A maioria os desclassificou, considerando-os atrasados e sem condições de frequentarem esse ciclo. Entretanto, as opiniões de alguns professores sobre esse projeto tenderam a ser positivas. Para aqueles professores que conheciam o projeto com mais profundidade (como os professores das Classes de Aceleração e os professores das classes comuns $-1^{\text {a }}$ a $4^{\text {a }}$ séries), as opiniões foram mais favoráveis pela compreensão dos fundamentos e, talvez, pela oportunidade que possuíam de acompanhar mais de perto o progresso dos alunos. Para os professores das $5^{\text {a }}$ a $8^{\text {a }}$ séries, as críticas eram mais contundentes, agressivas, não só sobre os alunos, mas também sobre os professores das 
Classes de Aceleração - um deles (professor de $5^{\text {a a }} 8^{\text {a }}$ séries) chegou a mencionar que "os docentes dessas classes são semianalfabetos e rebeldes", só para complementar.

Há opiniões divergentes dos professores sobre esses dois projetos: para alguns, uma manipulação do governo em relação aos dados estatísticos, afirmando que os projetos promoveram a não aprendizagem ou a má qualidade do ensino. Para outros, ocorreu uma correção no fluxo de alunos: acreditam que a progressão continuada possibilita sua valorização, bem como um melhor conhecimento sobre a prática desenvolvida pelos professores.

Em relação às professoras das Classes de Aceleração, segundo a coordenação da escola, a escolha levou em consideração seu perfil: paciência, disponibilidade, relacionamento carinhoso com os alunos, experiência com salas de alfabetização. As duas professoras só aceitaram trabalhar com a proposta porque tiveram a certeza de que contariam com todo o apoio da direção e da coordenação da escola e porque também participariam de um programa de capacitação.

Pelas entrevistas e observações realizadas em salas de aula, ficou evidente o compromisso e a paixão com que desenvolveram o trabalho e, ainda, um amálgama de sentimentos: medo, insegurança, otimismo, amor, confiança, esperança, coragem e seriedade, porque acreditavam na capacidade dos alunos, tratando-os de forma bastante carinhosa e acolhedora.

A compreensão da dureza da vida e das experiências negativas em relação à escola, à família e à sociedade demonstrou uma característica do "ser professor", tão bem defendida por Freire (1997) quando afirma:

\section{[...] é preciso juntar à humildade com que a} professora atua e se relaciona com seus alunos, uma outra qualidade, a amorosidade, sem a qual seu trabalho perde o significado. E amorosidade não apenas aos alunos, mas ao próprio processo de ensinar. Devo confessar que, sem nenhuma cavilação, não acredito que, sem uma espécie de "amor ar- mado", como diria o poeta Tiago de Melo, educadora e educador possam sobreviver às negatividades de seu que-fazer. Às injustiças, ao descaso do poder público, expresso na sem-vergonhice dos salários [...]. (p. 57)

A grande preocupação era com os alunos concluintes da Aceleração e que passaram para o $2^{\circ}$ ciclo, especialmente em relação aos que não atingiram as competências necessárias. Essas duas professoras sentiam insegurança, também, em relação ao tratamento dado por alguns professores, das $5^{\text {a }}$ a $8^{\text {a }}$ séries, a esses alunos, e apontavam para a importância de os professores compreenderem melhor essa proposta, para que fosse garantida uma forma diferenciada de trabalho com alguns alunos, como que em continuidade ao que havia sido feito por elas.

Em relação aos professores das $5^{\mathrm{a}}$ a $8^{\mathrm{a}}$ séries, alguns não faziam distinção entre os alunos que haviam participado das Classes de Aceleração e os das séries regulares, porque, na avaliação deles, de um modo geral, o desempenho escolar dos alunos não era considerado satisfatório, independentemente da sua origem. Criticavam, também, alguns professores que trabalhavam com as aulas de reforço, porque não tinham preparo nem muita experiência.

Outras afirmações foram feitas sobre as dificuldades que enfrentavam na escola como, por exemplo, a alta rotatividade dos professores - o que provocava insegurança nos alunos e uma desarticulação entre os conteúdos. Outra questão exposta refere-se ao número excessivo de aulas que acabavam assumindo, devido aos baixos salários, o que ocasiona uma sobrecarga de trabalho, prejudicando, inclusive, a avaliação realizada com os alunos: eles eram muitos e elas não conseguiam realizar nem um bom planejamento e organização de materiais para as aulas nem um sistema de avaliação com mais eficiência.

Alguns professores das $5^{\text {a }}$ a $8^{\text {a }}$ séries observaram que o que faltava também era um trabalho coletivo mais intenso e articulado, com mais discussões e estudos, que trouxesse alternativas para as dificuldades que enfrentavam. 
0 que pudemos verificar foi que somente as professoras das Classes de Aceleração e a coordenadora das séries iniciais participaram, efetivamente, de um programa de capacitação na delegacia de ensino. Apesar dos esforços da coordenadora na condução das reuniões de HTPC que eram oferecidas, a participação dos professores das séries iniciais era pequena. Em relação aos professores das $5^{\text {a }}$ a $8^{a}$ séries, também poucos participavam das reuniões de HTPC organizadas pela coordenação específica desse segmento. E sobre o preparo e as orientações para os professores acerca da implantação do regime de Progressão Continuada, nada houve de efetivo para os professores, apenas algumas orientações, na delegacia de ensino, para os coordenadores e diretores.

\section{A trajetória dos alunos e os encaminhamentos}

0 acompanhamento do percurso dos alunos nas séries escolares centrou-se nas duas CA 11 a partir de 1999 - último ano do Projeto na escola - até o fim do ano de 2001. 0 objetivo do estudo foi analisar a movimentação desses alunos durante três anos, a partir da série de origem, e os devidos encaminhamentos que receberam, tanto a partir da avaliação do desempenho nas CA 11 quanto em relação à avaliação nas séries regulares.

Para uma análise mais detalhada acerca da correção do fluxo idade-série dos alunos das CA 11 - já que esse foi o principal objetivo do Projeto -, foi necessário recuperar, de cada aluno, a idade e a série de origem a partir da inclusão deles nessas classes. Os Quadros 1 e 2 apresentam o número de alunos de cada Classe de Aceleração (manhã e tarde), a partir de 1999, com a idade dos alunos nesse ano; a série de procedência referente ao ano de 1998; os encaminhamentos nos anos de 2000 e 2001 com as idades dos alunos e as ocorrências do tipo transferência, abandono, retido por faltas, retido por insuficiência na aprendizagem e reclassificado.

A análise dos Quadros 1 e 2 evidencia que, dos 52 alunos matriculados em 1999, somente 22 alunos $(42,3 \%)$ continuavam na escola até o fim de 2001, ou seja, 30 alunos $(57,6 \%)$ saíram dela, estavam em situação de transferência (26 alunos - 50\%) ou estavam em situação de abandono (4 alunos - 7,6\%).

Analisando os dados sobre os encaminhamentos a partir das séries de procedência (1998) dos alunos nas CA 11 em 1999 até o fim de 2001, eles demonstram que, do ponto de vista da correção de fluxo idade-série, somente um aluno se beneficiou em relação à série de origem (ver o aluno no 7 no Quadro 1 de Movimentação da CA 11 do período da manhã).

Para melhor demonstração, o Quadro 3 apresenta seis diferentes situações da movimentação dos alunos das duas Classes de Aceleração, de 1999 a 2001, considerando, inclusive, a série de origem em 1998.

Como se pode observar, e revendo os Quadros 1 e 2 de movimentação dos alunos, especialmente na coluna dos Encaminhamentos de 2001 - ldade, exceto no caso do aluno $n^{\circ}$ 7 já citado, nenhuma outra situação demonstra avanço, correção ou progressão em relação à idade-série. Pelo contrário, as situações 2 e 6 comprovam que, da série de origem à série correspondente ao ano de 2001, os alunos cursaram quatro séries em quatro anos e, o pior: as situações 1, 3, 4 e 5 comprovam a retenção de alunos, enquanto as situações $1 \mathrm{e}$ 3 demonstram casos de alunos que permaneceram quatro anos na mesma série.

\section{As avaliações dos alunos nas $4^{a}, 6^{a}$ e $7^{a}$ séries em 2001}

Com a intenção de analisar o desempenho dos alunos que participaram do Projeto Classes de Aceleração em 1999 e que, em 2001, ainda permaneciam na escola, foi necessário realizar um levantamento para localizá-los nas diversas turmas. Os 22 alunos localizados estavam assim distribuídos na escola, pelas classes regulares, em 2001: 4 na $4^{\text {a }}$ série, 17 na $6^{\text {a }}$ série e 1 na $7^{\text {a }}$ série.

Os alunos receberam conceitos a cada bimestre a partir do desempenho que demons- 
Quadro 1: Quadro de Movimentação dos alunos da Classe de Aceleração ll - Manhã - 1999 a 2001.

\begin{tabular}{|c|c|c|c|c|c|}
\hline & & CLASSE DE & CELERAÇÃO 11 - & MANHÃ & \\
\hline Alunos & $\begin{array}{c}\text { ldade / } 1999 \\
\text { na CA II }\end{array}$ & $\begin{array}{c}\text { Série de } \\
\text { procedência / } 1998\end{array}$ & $\begin{array}{c}\text { Encaminhamento/ } \\
2000\end{array}$ & $\begin{array}{c}\text { Encaminhamento/ } \\
2001 \text { - ldade }\end{array}$ & Ocorrências \\
\hline № 01 & 12 anos & $4^{a}$ & $4^{a}$ & $4^{a}-14$ anos & Ret.p/insuf./00 \\
\hline № 02 & 11 anos & $3^{\mathrm{a}}$ & $4^{a}$ & $4^{a}-13$ anos & Ret.p/insuf./00 \\
\hline № 03 & 12 anos & $4^{\mathrm{a}}$ & $5^{a}$ & $6^{\mathrm{a}}-14$ anos & - \\
\hline № 04 & 11 anos & $3^{a}$ & $5^{a}$ & $6^{\mathrm{a}}-13$ anos & - \\
\hline № 05 & 12 anos & CA II & - & - & Transferência/99 \\
\hline № 06 & 12 anos & $3^{a}$ & - & - & Transferência/99 \\
\hline № 07 & 10 anos & $3^{\text {a }}$ & $5^{a}$ & $6^{a}-12$ anos & - \\
\hline № 08 & 12 anos & $3^{a}$ & - & - & Transferência/99 \\
\hline $\begin{array}{l}\text { № } 09 \\
\end{array}$ & 11 anos & $3^{\mathrm{a}}$ & $5^{a}$ & $6^{a}-13$ anos & - \\
\hline № 10 & 11 anos & $4^{\mathrm{a}}$ & $5^{a}$ & $6^{\mathrm{a}}-13$ anos & Transferência/01 \\
\hline № 11 & 11 anos & CA 11 & $4^{\mathrm{a}}$ & $4^{\mathrm{a}}-13$ anos & Ret.p/faltas/00 \\
\hline № 12 & 12 anos & $4^{\mathrm{a}}$ & $5^{a}$ & $6^{a}-14$ anos & Transferência/01 \\
\hline № 13 & 11 anos & $3^{a}$ & $4^{a}$ & $4^{a}-13$ anos & \begin{tabular}{|l|} 
Ret.p/insuf./00 \\
\end{tabular} \\
\hline № 14 & 16 anos & $3^{\mathrm{a}}$ & $5^{a}$ & $6^{a}-18$ anos & Transferência/01 \\
\hline № 15 & 11 anos & $4^{\mathrm{a}}$ & $5^{a}$ & $6^{\mathrm{a}}-13$ anos & - \\
\hline № 16 & 12 anos & $4^{a}$ & $5^{a}$ & $6^{a}-14$ anos & Transferência/01 \\
\hline № 17 & 12 anos & $4^{a}$ & $5^{a}$ & $6^{a}-14$ anos & - \\
\hline № 18 & 12 anos & $4^{a}$ & $5^{a}$ & $6^{a}-14$ anos & - \\
\hline № 19 & 11 anos & $3^{\mathrm{a}}$ & - & - & Transferência/99 \\
\hline № 20 & 11 anos & $3^{\mathrm{a}}$ & $5^{a}$ & $6^{a}-13$ anos & - \\
\hline № 21 & 13 anos & $4^{a}$ & $5^{a}$ & - & Abandono/00 \\
\hline № 22 & 14 anos & $4^{a}$ & $5^{a}$ & - & Transferência/00 \\
\hline № 23 & 11 anos & $3^{a}$ & $5^{a}$ & $6^{\mathrm{a}}-13$ anos & - \\
\hline № 24 & 11 anos & $3^{a}$ & $5^{a}$ & - & Transferência/00 \\
\hline
\end{tabular}

Quadro 2: Quadro de Movimentação dos alunos da Classe de Aceleração ll - Tarde - 1999 a 2001.

\begin{tabular}{|c|c|c|c|c|c|}
\hline \multicolumn{6}{|c|}{ CLASSE DE ACELERACCÃO $\|$ - TARDE } \\
\hline Alunos & $\begin{array}{c}\text { Idade /1999 na } \\
\text { CA ll }\end{array}$ & $\begin{array}{c}\text { Série de procedência } \\
/ 1998\end{array}$ & $\begin{array}{c}\text { Encaminhamento/ } \\
2000\end{array}$ & $\begin{array}{l}\text { Encaminhamento/ } \\
2001 \text { - ldade }\end{array}$ & Ocorrências \\
\hline № 01 & 12 anos & $4^{a}$ & - & - & Transferência/99 \\
\hline № 02 & 11 anos & $4^{a}$ & $5^{a}$ & $6^{\mathrm{a}}-13$ anos & - \\
\hline № 03 & 12 anos & $4^{\mathrm{a}}$ & $5^{a}$ & - & Transferência/00 \\
\hline № 04 & 11 anos & $4^{\mathrm{a}}$ & $5^{a}$ & $6^{a}-13$ anos & - \\
\hline № 05 & 12 anos & $4^{a}$ & $5^{a}$ & $6^{\mathrm{a}}-14$ anos & - \\
\hline № 06 & 11 anos & $4^{a}$ & $5^{a}$ & $6^{a}-13$ anos & Transferência/01 \\
\hline № 07 & 11 anos & $4^{a}$ & $5^{a}$ & $6^{a}-13$ anos & - \\
\hline № 08 & 12 anos & $4^{a}$ & $5^{a}$ & - & Transferência/00 \\
\hline № 09 & 15 anos & $4^{a}$ & - & - & Transferência/99 \\
\hline № 10 & 11 anos & $4^{a}$ & $5^{a}$ & $6^{a}-13$ anos & - \\
\hline № 11 & 12 anos & $4^{a}$ & - & - & Transferência/99 \\
\hline № 12 & 11 anos & $4^{a}$ & $5^{a}$ & $6^{a}-13$ anos & Transferência/01 \\
\hline № 13 & 12 anos & $4^{a}$ & $5^{a}$ & - & Transferência/00 \\
\hline № 14 & 12 anos & $4^{a}$ & - & - & Transferência/99 \\
\hline № 15 & 12 anos & $4^{a}$ & $5^{a}$ & $6^{a}-14$ anos & - \\
\hline № 16 & 12 anos & $4^{a}$ & - & - & Transferência/99 \\
\hline № 17 & 12 anos & $4^{a}$ & $5^{a}$ & $6^{\mathrm{a}}-14$ anos & Abandono/01 \\
\hline № 18 & 12 anos & $4^{a}$ & $5^{a}$ & $6^{a}-14$ anos & Transferência/01 \\
\hline № 19 & 12 anos & $4^{a}$ & $5^{a}$ & $6^{a}-14$ anos & Transferência/01 \\
\hline № 20 & 11 anos & $4^{a}$ & $5^{a}$ & $5^{a}-13$ anos & Ret. falt - Tr./01 \\
\hline № 21 & 11 anos & $4^{a}$ & - & - & Abandono/99 \\
\hline № 22 & 13 anos & $4^{a}$ & $5^{a}$ & $7^{\mathrm{a}}-15$ anos & Reclass. p/ 7as. \\
\hline № 23 & 12 anos & $3^{\mathrm{a}}$ & $5^{a}$ & $6^{a}-14$ anos & - \\
\hline № 24 & 11 anos & $4^{a}$ & $5^{a}$ & $6^{a}-13$ anos & Abandono/01 \\
\hline № 25 & 15 anos & $4^{a}$ & $5^{a}$ & $6^{a}-17$ anos & - \\
\hline № 26 & 12 anos & $3^{\mathrm{a}}$ & $5^{a}$ & $6^{a}-14$ anos & Transferência/01 \\
\hline № 27 & 12 anos & $3^{\mathrm{a}}$ & $5^{a}$ & $6^{a}-14$ anos & Transferência/01 \\
\hline № 28 & 14 anos & $4^{a}$ & $5^{a}$ & $6^{a}-16$ anos & Transferência/01 \\
\hline
\end{tabular}


Quadro 3

\begin{tabular}{|c|c|c|c|c|}
\hline Diferentes situações & 1998 & 1999 & 2000 & 2001 \\
\hline Situação 1 & CA ll & CAll & $4^{\mathrm{a}}$ & $4^{\mathrm{a}}$ \\
\hline Situação 2 & $3^{\mathrm{a}}$ & CAll & $5^{\mathrm{a}}$ & $6^{\mathrm{a}}$ \\
\hline Situação 3 & $4^{\mathrm{a}}$ & CAll & $4^{\mathrm{a}}$ & $4^{\mathrm{a}}$ \\
\hline Situação 4 & $4^{\mathrm{a}}$ & CAll & $5^{\mathrm{a}}$ & $5^{\mathrm{a}}$ \\
\hline Situação 5 & $4^{\mathrm{a}}$ & CAll & $5^{\mathrm{a}}$ & $6^{\mathrm{a}}$ \\
\hline Situação 6 & $4^{\mathrm{a}}$ & CAll & $5^{\mathrm{a}}$ & $7^{\mathrm{a}}$ \\
\hline
\end{tabular}

traram nas disciplinas: Língua Portuguesa, Matemática, Ciências, História, Geografia, Educação Física, Educação Artística e Inglês (exceto para os alunos da $4^{\text {a }}$ série). Os conceitos eram definidos por: PS - Plenamente Satisfatório; S Satisfatório; e NS - Não Satisfatório.

A análise das avaliações da maioria dos alunos revelou um desempenho insatisfatório durante o ano e, apesar disso, ao final de 2001, todos os alunos - egressos das Classes de Aceleração e das séries regulares - foram promovidos para as séries subsequentes.

De um modo geral, o desempenho dos alunos egressos das Classes de Aceleração se equiparou ao desempenho dos alunos regulares, e esse fato confirma os depoimentos de alguns professores, nas entrevistas, sobre a não distinção destes em relação aos demais, porque demonstraram o mesmo nível, e isso, por si só, é bastante positivo. No entanto, esse nível de aprendizagem não foi considerado pela coordenadora e pelos professores o desejado, ou mesmo suficiente, para alunos dessas séries, porque observaram que os alunos "escrevem e leem muito mal, falam muito errado, não produzem textos com coerência e coesão, e muitos não interpretam adequadamente as informações de um texto escrito", mesmo depois de participarem com assiduidade das aulas de reforço.

Ficamos com a sensação de que muitos continuam seus estudos, e até concluem um nível de ensino, como que "por acaso", sem a garantia da aquisição de saberes e da construção de conhecimentos, e isso confirma a reclusão dos excluídos, como um aprisionamento no sistema de ensino que lhes nega o direito a um ensino de qualidade.

0 que pudemos constatar com esse estudo é que o contexto analisado comporta al- gumas distinções. Em primeiro lugar, há professores mais envolvidos e comprometidos, do que outros, com a situação de muitos alunos marcados pelo fracasso escolar e procuram entendê-los em suas dificuldades. São mais tolerantes em relação aos comportamentos inadequados, demonstrando uma afetividade autêntica que se manifesta, especialmente, na forma como se relacionam com os alunos e expressam o prazer que sentem em fazer o que fazem - são professores.

As avaliações positivas que esses professores realizaram sobre alguns alunos que não foram bem avaliados por outros colegas nos confundem e levantam questões importantes sobre os critérios avaliativos: por que um professor difere tanto de outro em relação à avaliação do desempenho dos alunos?

Em segundo lugar, muitos professores demonstraram muita descrença na capacidade de alguns alunos (inclusive daqueles avaliados positivamente por outros professores), e isso causava uma tensão na relação entre os professores, que muitas vezes não reconheciam o trabalho desenvolvido - alguns acusavam seus pares de pouca seriedade nos critérios de avaliação adotados e se justificavam apontando, por exemplo, casos de alunos semianalfabetos que chegavam às $6^{\text {a }}$ ou $7^{\text {a }}$ séries, provocando uma relação pouco relevante deles com a coordenação, com a direção e com outros professores - porque insatisfeitos, descrentes, desestimulados.

Todavia, não abandonavam a profissão, continuavam ocupando um espaço que às vezes não se preenchia. Muitos, por conta desses sentimentos, adotavam uma postura de indiferença: chegavam à escola e davam suas aulas de qualquer jeito, avaliavam os alunos de qualquer forma, não se envolviam com as discussões postas nas reuniões de professores com a coordenação e, muitas vezes, nem participavam delas - "porque não tem jeito mesmo... os alunos vão passar de ano de qualquer maneira... cansei de conversar com os alunos e os pais... já tentei de tudo... não dá pra consertar agora coisas que deveriam ter sido corrigidas quando os alunos estavam na $1^{\text {a }}$ série... ninguém quer 
nada com nada..." -, e podemos inferir que essa atitude de desolação, somada à falta de um programa de capacitação e acompanhamento do trabalho dos professores pelos órgãos públicos, pode contribuir para a manutenção de uma situação nada importante para os alunos, que continuarão excluídos dos saberes e conhecimentos, que não serão absorvidos pelo mercado de trabalho, que não encontrarão reconhecimento de seus familiares sobre seus progressos escolares.

Essas considerações, que nos intrigam, apontam também para um descompasso no interior da escola, que se refere à inquietude dos professores especialmente no que se refere ao regime de progressão continuada - que os obrigou a rever suas opiniões e posições em relação à reprovação escolar. Parece-nos que estão convencidos de que reprovar um aluno não garante a aprendizagem, porque vivenciaram essa situação e puderam constatar que alunos que são reprovados sucessivamente não aprendem satisfatoriamente, da mesma forma que não estão aprendendo, também, quando passam para uma série subsequente, o que provoca, em muitos professores, a indignação de assistir a alunos chegando ao final das séries do Ensino Fundamental sem saber quase nada.

Percebemos, assim, o quanto é necessário que a escola promova discussões intensas sobre a avaliação, porque nos parece ser essa a grande vilã, ou heroína, dessa história: há de se lutar por um processo avaliativo não punitivo, não excludente, como o que marcava profundamente o destino de milhares de alunos de nossas escolas na época em que eram retidos sucessivamente e que marca agora, de um outro jeito, por uma promoção que muitas vezes não condiz com a necessária preparação para o enfrentamento da série subsequente.

0 risco de não se compreender a relação intrínseca entre ensino e avaliação pode estar gerando aquilo que pudemos observar na escola estudada: os professores estão "obedecendo" às novas orientações sobre a promoção dos alunos para as séries subsequentes - alguns acreditando ser bom para a autoestima dos alunos, outros criticando a medida e indignados com seu nível de aprendizagem -, mas não observamos alterações significativas em relação à aprendizagem dos alunos, que é considerada insatisfatória.

\section{Considerações finais}

A implantação das duas ações propostas pela SEESP - as Classes de Aceleração e o regime de Progressão Continuada - apresentam, nas suas intenções, o objetivo de combater a defasagem idade-série e o fracasso escolar. No entanto, o que pudemos constatar, na escola que acompanhamos, foi que essas ações não combateram nem uma nem outra coisa e, o que é pior, a quase inexistência de ações de acompanhamento e avaliação dessas propostas ou mesmo de formação continuada por parte dos órgãos centrais deixou a escola à deriva.

Pudemos sentir a angústia da coordenação e de alguns professores que "não sabem mais o que fazer", especialmente em relação aos alunos que não conseguem aprender e que vão seguindo nas séries do Ensino Fundamental.

Alguns professores, especialmente os das Classes de Aceleração, conseguem enxergar algo de positivo nisso tudo quando apontam a elevação da autoestima dos alunos, porque não estão mais sendo reprovados. Esse é um outro perigo que se descortina porque, na ânsia de minimizarem as mazelas da vida de muitos alunos e o próprio estigma do fracasso, podem promover um reconhecimento dos avanços observados em relação à aprendizagem dos alunos, mas que ainda não são suficientes para corrigir a defasagem que muitos apresentam.

[...] a ênfase na "promoção da autoestima" pode ter desviado mais uma vez a atenção dos educadores do papel da escola na socialização competente de "conhecimentos" e fez da "melhora da autoestima" o último grito do discurso educacional hegemônico. (Patto, 2000b, p. 195) 
A implantação dessas propostas (da forma como ocorreu), o acompanhamento e a preparação dos professores (que não ocorreu como deveria) e os efeitos observados (que não deveriam ocorrer) nos levam a acreditar, mais ainda, naquilo que já foi discutido e que é necessário marcarmos pontualmente: a exclusão permanece na escola; os alunos estão inseridos, mas não pertencem a ela; a escola não está se mostrando democrática em relação à aquisição dos saberes necessários. Em outras palavras,

[...] democratizar a escola significa, nessas reformas, muito mais pôr em andamento a marcha pelos sucessivos graus escolares, sem reprovações, do que oferecer uma boa formação intelectual. Na concepção dos planejadores, democratizar a escola tem sido principalmente abrir a porta trancada das séries subsequentes, importando pouco a qualidade do ensino oferecido. (Patto, 2000b, p. 195)

Além disso, não garantiram também um trabalho coletivo articulado, com orientações, subsídios e acompanhamento da prática peda- gógica. 0 que se observou foram poucas ações com o envolvimento de alguns professores, desvelando a insuficiência para a melhoria de resultados no desempenho dos alunos. Contudo, não podemos acreditar em impossibilidades, apesar das inúmeras dificuldades que o cotidiano de muitas escolas nos apresenta. Precisamos, sim, compreender cada vez mais a realidade da nossa escola pública, inserida num contexto social mais amplo. Devemos prestar mais atenção às políticas educacionais que surgem - que nem sempre consideram a história e a memória de nossas escolas e dos nossos professores - e que provocam, muitas vezes, uma desarticulação, uma descontinuidade dos trabalhos que vinham sendo desenvolvidos pelos professores e, ainda, uma desmobilização do conjunto dos profissionais e da própria organização e estrutura da escola, além de não assegurarem a implementação de recursos humanos e materiais para a efetividade das intenções anunciadas. A escola não pode se responsabilizar ou mesmo resolver sozinha o problema da exclusão dos indivíduos, mas pelo menos pode ser capaz de não ampliá-lo.

\section{Referências bibliográficas}

AZANHA, J. M. P. Comentários sobre a formação de professores em São Paulo. In: Formação de professores. São Paulo: UNESP, 1998.

BAHIA, N. P. Enfrentando o fracasso escolar: inclusão ou reclusão dos excluídos? São Paulo, 2002. 120 p. Tese (Doutorado). Pontifícia Universidade Católica de São Paulo. São Paulo, 2002

BRASIL. Ministério da Educação e do Desporto. Relatório de Acompanhamento do Trabalho nas Classes de Aceleração. Brasília, 1998.

FERRAR0, A. R. Diagnóstico da escolaridade no Brasil. Revista Brasileira de Educação, n. 12, ANPED, p. 22-47, set./dez. 1999.

FREIRE, P. Professora sim, tia não: cartas a quem ousa ensinar. 8. ed. São Paulo: Olho d’Água, 1997.

GENTILI, P. A. A. (Org.). Pedagogia da exclusão - crítica ao neoliberalismo em educação. 4. ed. Petrópolis: Vozes, 1998.

KLEIN, R.; RIBEIRO, S. C. 0 censo educacional e o modelo de fluxo - 0 problema da repetência. Revista Brasileira de Estatística, v. 52, n. 197-198, p. 5-45, jan./dez. 1991.

A pedagogia da repetência ao longo das décadas. Ensaio: Avaliação das Políticas Públicas em Educação. Rio de Janeiro, v. 3, n. 6, jan./mar. 1995. 
NÓVOA, A. (Coord.). As organizações escolares em análise. Lisboa: Dom Quixote, 1992a.

Os professores e a sua formação. Lisboa: Dom Quixote, 1992b.

PATTO, M. H. S. A produção do fracasso escolar: histórias de submissão e rebeldia. São Paulo: Casa do Psicólogo, 2000a. (1. ed., 1990 - T. A. Queiroz Editor Ltda.).

Mutações do cativeiro - escritos de psicologia e política. São Paulo: Hacker/Edusp, 2000b.

PLACCO, V.; ANDRÉ, M.; ALMEIDA, L. Estudo avaliativo das classes de aceleração na rede estadual paulista. Cadernos de Pesquisa, São Paulo, n. 108, FCC/Cortez, nov. 1999.

SÃO PAULO (Estado). Secretaria da Educação. Decreto n. 40.473, de 21/11/1995. Institui sobre o Programa de Reorganização das Escolas da rede pública. Diário Oficial do Estado, v. 105, n. 222, 22 nov.1995, Seção I.

Deliberação CEE n. 09/97. Institui o Regime de Progressão Continuada no Ensino Fundamental. Diário Oficial do Estado, 05/08/1997. Disponível em: <http://www.doesp.net/estadual.html\#0018>. Acesso em: 20.fev.2008.

ZEICHNER, K. M. A formação reflexiva dos professores: idéias e práticas. Lisboa: Educa, 1993.

Recebido em 01.04.08

Aprovado em 06.05.09

Norinês Panicacci Bahia é docente pesquisadora do programa de pós-graduação em Educação e coordenadora do curso de Pedagogia a Distância da UMESP. 